illustrating the principles of inelastic and elastic demand respectively, and taking salt and margarine as examples, might extend the study into the relative stability of employment in geographical areas supplying one as compared with those dependent on the other, to account for their differences. This would be an excellent geographic verification or illustration of the theory. The principle of substitution might well be illustrated by the rise to popularity of particular commodities supplanting others the costs of which had become dearer, relatively, if not absolutely. This change means a change in the economic statistics of geographical areas, which can be examined and stated.

International trade proceeds on the theory of comparative costs (with certain important modifications) and it shows that it is quite possible for $a$ to export to $b$ commodities in which $b$ has the greater natural advantage, provided that $b$ 's natural advantages in another commodity are even greater. This ought to be susceptible of verification by reference to geographic facts.

Geography has little concern with money, banks or the technique of trade, and productive methods, but I would not conclude that the economist can make no use of geography at all in these fields. Atkinson says: "But if the metric system gives Germany an advantage over Great Britain in South American markets, it becomes to that extent a factor in the Geographic division of labour-that is, it tends to locate the economic complement of the wheat fields, and cattle ranches of Argentina in Germany rather than England."

Then again, banking systems may affect geographic facts: if the bank reserve system in America draws money from country to cities and gives them a lower interest rate, then it becomes a factor in concentrating industries, and determin. ing the geographic division of labour.

Technical production is not economic geography. But if the Bessemer process causes migration of the steel industry to areas where the ores are free from certain impurities, it is part of economic geography.

A few years ago the American Economic Association had a round table discussion on the various relations between economics and geography ${ }^{1}$. It covered the geographic basis of agricultural production, land economics, economic concept of property in minerals, the study of pioneer belts, and geography in foreign trade prospects.

This probably expresses fairly the field of geography which actually lies within the field of economic theory, but the range of the latter is extensive and may--to reverse the metaphorthrow valuable side-lights at unexpected points of geography. But economics, though now highly specialized, is really one and indivisible. The geographer who aims at strengthening his grasp of causality, especially for expository purposes, by learning economics, would do well to cover the whole field first, in a preliminary way, and then specialize on the particular applications to which our analysis has led us. The economist who would keep his feet on the ground, even if his head is in the clouds, by realistic treatment, will get no such mitigations of his task from the geographer-like John Wesley, he will take the whole world for his parish.

\footnotetext{
${ }^{1}$ Proceedings of the American Economic Association, March, 1926,
} p. 112 .

\title{
Constitution of the Earth*
}

\section{By J. H. Reynolds}

$\mathrm{T}$ $\mathrm{HE}$ behaviour of materials such as granite and basalt can be tested in the laboratory up to a pressure of 30,000 atmospheres, or, as engineers would say, about 200 tons to the square inch. This corresponds to a depth of $120 \mathrm{~km}$. in the earth's crust, but what are the conditions of matter at pressures of 10,000 tons to the square inch or thereabouts, which presumably must obtain near the centre of the earth? Then with regard to temperature, we know that near the surface of the earth in Europe this increases generally with depth by about $30^{\circ} \mathrm{C}$. per $\mathrm{km}$. The rate of increase

- Extract from the presidential address to the Royal Astronomica Society delivered on the presentation of the Gold Medal to Dr. Harold Jeff reys on February 12. differs considerably from one point of the earth's surface to another. In North America it is three quarters of this amount, and in South Africa only about one half. In regions where volcanic activity has taken place in recent geological times, the rates of increase are abnormally high. In a boring almost a kilometre deep at Budapest a temperature of $69^{\circ} \mathrm{C}$. was reached at the bottom. In Tuscany and other places in Italy a similar rate of increase has been found. If we take an average and extra. polate from this, we find that at a depth of something like $50 \mathrm{~km}$. we reach a temperature of $1,400^{\circ} \mathrm{C}$., - - enough to fuse all but the most re. fractory substances. 
But is it safe to extrapolate, and would not the increase in pressure alter the fusing point and also the rigidity? This undoubtedly takes place, for earthquake foci as deep down as 400-500 km. have been inferred from the various types of seismic waves and their times of travel to different stations. An earthquake focus at such a depth presupposes that the material there is strong enough to fracture, so we must assume that notwithstanding the probability of a temperature certainly equal to, and probably much more than, the free fusing point, the material, whatever it is, has still considerable strength.

Then we have the complication introduced by radioactivity. A certain proportion of the earth's internal heat, at any rate in the outer crust, is due to the presence in igneous rocks of radioactive metals such as uranium and potassium. What proportion of the earth's internal heat is due to this cause, and how much to primeval heat still remaining from the time when the whole earth was a molten globe?

The deductions which geophysicists can make as to the internal structure and composition of the earth, below such an insignificant fraction of the earth's radius as a few kilometres, must therefore be in the nature of extrapolations, and the validity of the conclusions reached depends entirely on the assumptions made as to the behaviour of various substances under conditions of heat and pressure which are for the most part far beyond the limit of verification in the laboratory.

Notwithstanding these formidable difficulties, Dr. Harold Jeffreys has boldly grappled with the many problems involved, and has presented us with a conception of the earth's interior which fits in remarkably well with the known data. $\mathrm{He}$ first of all postulates a shell which behaves mechanically as a solid, reaching down as far perhaps as $3,000 \mathrm{~km}$. This shell is of a density which increases from the surface downwards, the surface density being about $2 \cdot 7$ and the lowest layer about 5. It is worth noting at this point that Jeffreys' work is quite inconsistent with Wegener's hypothesis of the continents floating on a viscous magma comparatively near the surface, and it is equally opposed to the tetrahedral theory of the formation of the continents. There is a discontinuity between the central core and the shell in the way of transmitting earthquake waves, and as the core is apparently incapable of transmitting distortional waves at all, it is concluded that the central core is still in a molten condition. Its density is only consistent with the heavier metals, and iron is probably its principal constituent.

From a detailed study of the times and rates of travel of the two main types of earthquake waves, the primary and the secondary, with their associated surface waves, it is suggested that the principal constituent of the earth's solid shell is olivine, as this mineral is of about the right density required. But this does not extend to the surface, where there is a layer of granite under the accumulated sedimentary rocks of the continents, and a layer of denser rocks, presumably basic, lies under the oceans. The granitic or continental layer is estimated to be about $10 \mathrm{~km}$. thick, and two other layers of about the same thickness, but discontinuous in their density, may lie between it and the lower shell of olivine or its equivalent.

Stoneley has also made an estimate of two discontinuous surface layers, and he finds a thickness of $12 \mathrm{~km}$. for the granitic layer and $24 \mathrm{~km}$. for the intermediate layer. There seems to be another discontinuity of density at something like $400 \mathrm{~km}$. down.

In substances that contract on solidifying, the fusing point is raised by pressure, so that at great depths materials must be still solid at temperatures much higher than the fusing points at the surface. This rise in the melting point due to pressure at low pressures is about $3^{\circ}$ per kilometre, at greater depths probably somewhat less than this. While the earth was molten, the temperature would increase downwards, but the fusing point would increase faster, and as the whole cooled at a uniform rate, so solidification must have taken place from the bottom upwards. If the core is of metals, which have a lower fusion temperature than the basic silicates of which the outer shell probably consists, then the core would remain liquid, while the outer shell, still liquid at the surface, would be solid at great depths. The core, therefore, got trapped under a layer of badly conducting silicates, and its temperature has not dropped greatly since it was originally formed. On this hypothesis the whole process of solidification did not take more than some tens of thousands of years.

It is now established that the earth's surface temperature is practically controlled by solar radiation alone, and it has been so during the greater part of geological time. If we find evidence of variation in surface temperatures in past geological epochs, we must attribute the variation either to changes in the sun's radiation or to altered meteorological conditions. I find it difficult to imagine altered general meteorological conditions without a corresponding cause in solar radiation.

The small amount of heat still leaving the earth by conduction from the interior is partly a relic of the primeval heat from great depths, and partly heat generated more recently by radioactivity. The radioactive metals, uranium, thorium and potassium are found in all surface rocks in minute 
but measurable amounts. Granite contains a greater proportion of these radioactive metals than the basic rocks. In average granite the rate of generation of heat is found to be $1.3 \times 10^{-12}$ calories per cubic centimetre per second, while for basalt it is only $0.50 \times 10^{-12}$ ealories. Small as these amounts are, it is found that the total heat now being lost from the earth by conduction can be supplied by a layer of granite $20 \mathrm{~km}$. thick over the whole surtace. This leaves nothing to be supplied from greater depths, and fixes an upper limit for the thickness of the granite layer. But it has been found from the study of near earth- quakes and surface waves that the granitic layer is only $10 \pm 3 \mathrm{~km}$. thick There must be, therefore, as large a proportion of radioactive elements in the upper $10 \mathrm{~km}$. as in all the rest of the solid shell beneath it. This leads to the conclusion that radioactivity decreases rapidly with depth, and further that the radioactive metals became concentrated in the surface rocks in the early history of the earth. In any event, volcanoes and subterranean igneous phenomena such as intruded masses of granite and basalt must have some source of heat not a great distance down to explain them, and radioactivity in the earth's crust does this.

\section{Obituary Notices}

Dr. F. S. Macaulay, F.R.S.

$\mathrm{H}^{\mathrm{R}}$ RANCIS SOWERBY MACAULAY, who died at Cambridge on February 9, aged seventy-four years, was for many years mathematical master at St. Paul's School and will be remembered by generations of pupils, not a few of whom became distinguished mathematicians; he also produced original mathematical work of high quality, in a field little cultivated in Fngland, the general theory of algebraic polynomials.

Macaulay was the son of the Rev. Samuel Macaulay, and was born at Witney, Oxfordshire, on February II, 1862. From Kingswood School, Bath, he went up to St. John's College, Cambridge, in 1879, and was bracketed eighth wrangler in Parts $I$ and $X X$ of the Mathematical Tripos in June 1882, the first year of the divided tripos. In the January following he was placed in the third division of the new Part III, to which only wranglers were admitted. After two years at his old school, he was in 1885 appointed to a mastership at St. Paul's, where he remained until his retirement in 1911. Before going to Cambridge he had passed the London Matriculation with honours; he took the London B.Sc. in 1891, and the D.Sc. in 1897. He published, in 1895, a text-book on "Geometrical Conics". He was an active member of the Mathematical Association, being for many years an associate editor of the Mathematical Gazette. After the Great War he went to live in Cambridge, where, in 1923, he married Norah, widow of $\mathrm{Mr}$. G. A. Matthew.

Macaulay approached his algebraic research from the geometrical side, the theory of algebraic curves. His first paper, of fifty pages, published in the Proceedings of the London Mathematical Society (26; 1895), is concerned with the number of conditions presented by a finite set of points in a plane, grouped in 'clusters' of any degree of complication, in the determination of algebraic curves of given order. This led on to an algebraic investigation of the intersections of curves at multiple points and to a thorough roinvestigation of the well-known theorem of Noether on the form of the equation of a curve which passes through the intersections of two curves, with the generalizations of Lasker. So his interest was aroused in the general theory of modular systems, that is, of polynomials, in any number of variables, expressible in the form $A_{1} F_{1}+\ldots+A_{r} F_{r}$, there the $F$ 's are given polynomials and the $A$ 's are arbitrary polynomials. A series of papers in the Proceedings of the London Mathematical Society, the Transactions of the American Mathematical Society, and the Mathematische Annalen was followed in 1916 by his Cambridge Tract, "The Algebraic Theory of Modular Systems", in which he gave an account of the whole subject, filling in many gaps in the proofs of his predecessors, and adding considerably to the theory.

Macaulay's work attracted more attention in Germany than in Great Britain, and it was not until 1928 that its first-rate quality was recognized by his election to the Royal Society. In his later years, in Cambridge, he lived a retired life, and was not often seen in College or in society, but he always showed a keen interest in the work of the younger mathematicians on the algebraical and geometrical side, and was a frequent and welcome visitor at seminars in these subjects.

We regret to announce the following deaths :

Dr. Frederick V. Coville, botanist of the U.S. Department of Agriculture, known for his work on the relation of plant growth to soil conditions, on January 9, aged sixty-nine years.

Sir Reginald Craddock, member of Parliament for the Combined English Universities since 1931, on February 10, aged seventy-two years.

Dr. Alfred Daniell, author of the well-known "Text. book of the Principles of Physics", on January 12, aged eighty-three years.

Prof. Max C. W. Weber, For. Mem. R.S., formerly professor of zoology and comparative anatomy in the University of Amsterdam, on February 7, aged eighty-four years. 